\title{
La Asamblea Constituyente y sus funciones en el sistema democrático constitucional
}

A Karina Cuba

Omar Cairo Roldán*

\section{Introducción}

Con motivo de las elecciones presidenciales y parlamentarias realizadas en el Perú entre abril y junio del año 2006, se presentaron propuestas relativas a la instalación de una Asamblea Constituyente. Estas tuvieron como punto de partida el cuestionamiento al origen de la Constitución de 1993, elaborada por un Congreso Constituyente Democrático (CCD) convocado por un gobierno de facto.

Frente a esta circunstancia resulta oportuno revisar, desde la doctrina y la historia constitucionales, cuáles son las funciones que cumple una Asamblea Constituyente en un sistema democrático constitucional. Estas funciones se concretan en dos momentos específicos de la vida política de una sociedad: durante el ejercicio del poder constituyente, y en la realización de una reforma constitucional.

\section{El concepto del poder constituyente}

Entendemos como poder constituyente la atribución que corresponde a las personas para establecer el reconocimiento de sus derechos fundamentales y para elaborar la estructura organizativa concreta del sistema democrático constitucional de su sociedad política. Su ubicación se encuentra, por lo tanto, en la «[...] fase creativa de la normatividad constitucional». ${ }^{1}$

* Abogado. Profesor de Derecho Constitucional de la Facultad de Derecho de la Pontificia Universidad Católica del Perú.

1 Ramírez Cleves, Gonzalo A. Límites de la reforma constitucional en Colombia. El concepto de Constitución como fundamento de la restricción. Bogotá-Colombia: Universidad Externado de Colombia, 2005, p. 285. 
Respecto de los orígenes históricos del concepto de poder constituyente, Antonio Negri afirma lo siguiente:

El término ha sido probablemente introducido por primera vez, en el curso de la revolución americana, pero ello está dentro del desarrollo del pensamiento político de los siglos del renacimiento, entre el quince y el dieciocho, como noción ontológica de la capacidad formativa del movimiento histórico. Cuando también la idea de revolución sea sometida al dominio de los astros o a la necesidad del ciclo polibiano de los regímenes políticos — "I have seen in this revolution a circular motion»- también ella constituye ya «le fond mobile de la science humaine», de aquella nueva ciencia que "constituye» la historia. $\mathrm{Y}$ he aquí que, después de 1789, revolución y poder constituyente entran sobre la gran escena de la historia y del pensamiento moderno como indisolubles caracteres de la actividad humana transformadora [...]. (sic) ${ }^{2}$

En el contexto de los hechos que provocaron la Revolución Francesa, referido por Antonio Negri, la formulación de la teoría del poder constituyente fue realizada por Emmanuel Sieyès, en su obra ¿Qué es el Tercer Estado? En la cual afirma que la nación es un «[...] cuerpo de asociados que viven bajo una ley común y representados por una misma legislatura», ${ }^{3}$ Sieyès sostuvo también que estos asociados — iguales entre sí — «[...] se ponen de acuerdo acerca de las necesidades públicas y los medios para satisfacerlas», ${ }^{4}$ pero debido a que «[...] son demasiado numerosos y se hallan repartidos en una superficie demasiado extensa como para ejercer por sí mismos fácilmente la voluntad común», definen «[...] lo necesario para velar y proveer a las ocupaciones públicas, y confían el ejercicio de esta porción de voluntad nacional, y por tanto de poder, a alguno de entre ellos». ${ }^{6}$ De esta manera, los asociados — es decir, la nacióncrean un "gobierno" ejercido por procuración.

Luego de ello, Sieyès explicó lo que debe entenderse por «[...] constitución política» de una nación y como definir sus "[...] justas relaciones con la propia nación». ${ }^{8}$ Para Sieyès la constitución de un cuerpo es la organización, las formas y las leyes propias para el cumplimiento de las funciones a las que ha sido destinado, y es evidente que «[...] todo gobierno comisionado debe tener su

2 NeGRI, Antonio. El poder constituyente. Ensayo sobre las alternativas de la modernidad. España: Libertarias / Prodhufi S.A.,1994, pp. 44-45.

3 SIEY⿸̇s, Emmanuel. ¿Qué es el Tercer Estado? Ensayo sobre los privilegios. Madrid: Alianza Editorial S.A., 1989, p. 90.

Ibíd., p. 142.

lbíd.

Ibíd., pp. 142-143.

Ibíd., p. 143.

Ibíd., p. 144. 
constitución». Con este punto de partida, sostuvo que corresponde a la nación, en ejercicio de su poder constituyente, organizar su cuerpo gubernativo, es decir, otorgarse una Constitución. Según este autor, esta Constitución, compuesta por las leyes llamadas fundamentales de la nación, «[...] no es obra del poder constituido sino del poder constituyente», razón por la cual dichas leyes no pueden ser modificadas por los cuerpos que existen y actúan a través de ellas. ${ }^{9}$

A partir de lo expuesto por Sieyès, la diferencia entre los conceptos de poder constituyente y poder constituido puede ser comprendida. El poder constituyente es la atribución de los miembros de una sociedad política para adoptar una Constitución, es decir, una estructura organizativa para su gobierno, mientras que el poder constituido es el poder político que ejerce cada uno de los órganos que integran esta estructura, de conformidad con las reglas previstas en ella. Actualmente, en el Perú — por ejemplo— el poder que ejercen el Congreso, el presidente de la República y el Poder Judicial, de conformidad con la Constitución peruana vigente, no son manifestaciones del poder constituyente sino del poder constituido.

Además de lo expuesto, Sieyès también sostuvo que los miembros de una sociedad política pueden modificar la Constitución que ellos mismos han aprobado, porque «[...] una nación no puede ni alienarse, ni prohibirse el derecho de querer algo; y cualquiera que sea su voluntad, no puede perder el derecho a cambiarla si su interés lo exige». ${ }^{10}$ Más adelante, intentaremos explicar cómo es posible distinguir la modificación de una Constitución realizada en ejercicio del poder constituyente, de los cambios que se realizan utilizando el instrumento de la reforma constitucional.

\footnotetext{
Sieyès explica la creación de la Constitución por parte de la nación, en ejercicio del poder constituyente, en los siguientes términos: «Pero que no se nos diga según qué criterios, según qué intereses habría podido otorgarse una constitución a la nación misma. La nación existe ante todo, es el origen de todo. Su voluntad es siempre legal, ella es la propia ley. Antes y por encima de ella sólo existe el derecho natural. Si queremos hacer una idea justa de la serie de leyes positivas que pueden emanar de su voluntad, vemos en primera línea las leyes constitucionales que se dividen en dos tipos: unas regulan la organización y las funciones del cuerpo legislativo, otras determinan la organización y las funciones de los diferentes cuerpos activos. Estas leyes son Ilamadas fundamentales, no porque puedan Ilegar a ser independientes de la voluntad nacional, sino porque los cuerpos que existen y actúan a través de ellas no pueden modificarlas. En ambos casos, la constitución no es obra del poder constituido, sino del poder constituyente. Ningún tipo de poder delegado puede cambiar lo más mínimo las condiciones de su delegación. Las leyes constitucionales son, en ese sentido, fundamentales. Las primeras, las que establecen la legislatura, son fundadas por la voluntad nacional antes de toda constitución; suponen su primer grado. Las segundas deben ser establecidas por una voluntad representativa especial. Así, todas las partes del gobierno se remiten y dependen, en último término, de la nación. No planteamos aquí más que una idea fugaz, pero exacta». En SIEYÈs, Emmanuel. Ob. cit., pp. 145-146.

$10 \quad$ lbíd., p. 148.
} 
Desde que se formuló la idea del poder constituyente, este concepto se ha enriquecido. Por eso, su ejercicio permite que se produzcan cambios trascendentes en la organización del ejercicio del poder político cuando existe consenso para realizarlos, pero los mecanismos de la reforma constitucional resultan insuficientes para lograrlo. Sin embargo, hay un elemento que no podrá ser eliminado mediante el ejercicio del poder constituyente. Este elemento es la democracia constitucional, es decir, el sistema genérico que, mediante la distribución de las funciones políticas entre distintos órganos y el control de su ejercicio, permite proteger los derechos de las personas.

\section{El poder constituyente como integrante de la democracia constitucional}

La teoría del poder constituyente elaborada por Sieyès es un componente del sustento de la Revolución Francesa, es decir, de un movimiento cuyo resultado trascendente fue el establecimiento de la democracia constitucional. Son elementos fundamentales de este sistema político el reconocimiento de los derechos de las personas y la distribución del ejercicio de las funciones políticas entre distintos órganos, así como el control de este ejercicio, como instrumento para la protección de estos derechos. Estableciendo el vínculo inescindible entre la Constitución de una sociedad política y este contenido de la democracia constitucional, Sieyès sostuvo en la Asamblea Nacional Constituyente lo siguiente:

La Constitución abraza al mismo tiempo la formación y la organización interior de los diferentes poderes públicos, su correspondencia necesaria, y su independencia recíproca. En fin, las precauciones políticas de las que es inteligente rodearlos con la finalidad de que, siendo siempre útiles, no puedan jamás convertirse en peligrosos. Tal es el verdadero sentido de la palabra Constitución, el relativo al conjunto y a la separación de los poderes públicos. ${ }^{11}$

Y también:

Nosotros tenemos por principio fundamental y constitucional que la legislatura ordinaria no podrá en ningún caso ejercitar el poder constituyente ni tampoco el poder ejecutivo. Esta separación de poderes resulta de la más absoluta necesidad $[\ldots] .^{12}$

11 Citado por Blanco Valdés, Roberto L. En: El valor de la Constitución. Separación de poderes, supremacía de la ley y control de la constitucionalidad en los orígenes del Estado liberal. Madrid: Alianza Editorial S.A., 1998, p. 218.

12 Citado por Blanco Valdés, Roberto L., ob. cit., p. 220. 
El reconocimiento de estos elementos de la democracia constitucional quedó inscrito en el artículo 16 de la Declaración de los Derechos del Hombre y del Ciudadano de 1789. Ahí se estableció que "Toda sociedad en la que la garantía de los derechos no está asegurada ni la separación de poderes establecida, no tiene constitución». ${ }^{13}$

La estructura organizativa concreta del sistema democrático constitucional en una sociedad política —-denominada forma de gobierno o régimen políticose encuentra contenida en su Constitución. Así, por ejemplo, en un país se puede adoptar un régimen presidencial — como en Estados Unidos-, un régimen parlamentario - como en Inglaterra- o cualquier otra forma de gobierno correspondiente a este sistema político —en el Perú, por ejemplo, está vigente un régimen semipresidencial- En este contexto, el poder constituyente resulta un elemento fundamental de este sistema, porque permite a las personas decidir cuál es la estructura organizativa concreta de la democracia constitucional que van a utilizar en su sociedad política.

Como se puede apreciar, el poder constituyente es una expresión de autogobierno de las personas. Por consiguiente, no puede ser utilizado válidamente por estas para renunciar a la posibilidad de decidir libremente acerca de la organización de su gobierno. Esta renuncia se produciría si las personas, invocando este poder, optaran por un sistema autocrático, es decir, por una organización en la cual el ejercicio de más de una función política estuviera en manos de un solo órgano del Estado. Se trataría de una renuncia a la posibilidad futura del ejercicio del poder constituyente, porque la concentración de las funciones políticas cancela la posibilidad material de que las personas decidan de forma auténtica y libre acerca de la estructura organizativa del gobierno de su sociedad. En esta hipótesis —utilizando los términos de Sieyès—, las personas estarían prohibiéndose el derecho de querer algo y de cambiar si su interés asi lo exige.

Sin embargo, la idea del poder constituyente ha sido utilizada, frecuentemente, como la justificación de la existencia de cualquier sistema político diferente de la democracia constitucional. Carl Schmitt, por ejemplo, afirmó que el poder constituyente es la «[...] voluntad política cuya fuerza o autoridad es capaz de adoptar la concreta decisión de conjunto sobre modo y forma de la propia existencia política, determinando así la existencia de la unidad política como un todo». ${ }^{14}$ Además, como punto de partida de esta definición, utilizó un concepto de Constitución según el cual esta contiene solo «[...] la determinación consciente de la concreta forma de conjunto por la cual se pronuncia o

13 Declaración de Derechos del Hombre y del Ciudadano. En F. Javier Díaz Revorio (comp.). Textos constitucionales históricos. Lima: Palestra Editores, 2004, p. 129.

14 Sснмıтt, Carl. Teoría de la Constitución. Madrid: Alianza Editorial S.A., 1982, pp. 93-94. 
decide la unidad política», ${ }^{15}$ forma de conjunto que — según este autor- puede ser una democracia constitucional o cualquier otro sistema político. Así, Schmitt mencionó que en Rusia (1918) se presentó con la mayor claridad el «[...] carácter de la Constitución como una decisión consciente» ${ }^{16}$ y que la «[...] Constitución francesa de 1852 contiene la decisión del pueblo francés a favor del Imperio hereditario de Napoleón III». ${ }^{17}$

Como podemos apreciar, el autor mencionado le atribuye al poder constituyente un significado incompatible con la democracia constitucional. Por eso, Gonzalo Ramírez Cleves precisa que Carl Schmitt «[...] tilda de meras concepciones ideales - Constitución ideal - a toda la dogmática que pretenda justificar el fenómeno constitucional desde la perspectiva de la soberanía democrática y del Estado de Derecho». ${ }^{18}$ Agrega que la confianza en el decisionismo exacerbado, presente en la Teoría de la Constitución de Schmitt, «[...] en últimas pretende soslayadamente crear la duda de la legitimidad de un sistema basado en democracia, que autorizaría, con base en la decisión política fundamental, cualquier sistema político así se encuentre este al margen del Estado democrático de derecho». ${ }^{19}$ Finalmente, explica que, utilizando las perspectivas de Carl Schmitt, «[...] la constitución material, por ejemplo del Volk alemán, sería la voluntad de un Führer, o la de popolo italiano sería encarnada en un Duce, con lo que se niegan por completo los presupuestos básicos para el entendimiento de una Constitución: la democracia y la libertad, esta última conformada por la garantía de los derechos y la división del poder». ${ }^{20}$

Teniendo presente los presupuestos de la Teoría de la Constitución de Carl Schmitt, no resulta sorprendente que este autor haya afirmado en 1934, respecto de la dictadura nacionalsocialista, lo siguiente:

El Führer está defendiendo el ámbito del derecho de los peores abusos al hacer justicia de manera directa en el momento del peligro, como juez supremo en virtud de su capacidad de líder. «En ese momento yo era el responsable del destino de la nación alemana y por ende el juez supremo del pueblo alemán». El auténtico líder siempre es también juez. De su capacidad de líder deriva su capacidad de juez. Quien pretende separar ambas capacidades o incluso oponerlas entre sí convierte al juez en líder opositor o en instrumento del mismo y busca

\footnotetext{
15 Ibíd., p. 46.

16 Ibíd.

17 Ibíd., p. 47.

18 Ramírez Cleves, Gonzalo. Los límites a la reforma constitucional y las garantías-límites del poder constituyente: los derechos fundamentales como paradigma. Bogotá-Colombia: Instituto de Estudios Constitucionales Carlos Restrepo Piedrahita, 2003, pp. 36-37.

19 Ibíd., pp. 37-38.

${ }^{20}$ Ibíd., p. 38.
} 
desquiciar al Estado con la ayuda de la justicia. Se trata de un método aplicado con frecuencia no sólo para destruir el Estado sino también el derecho. ${ }^{21}$

Sobre la base de los mismos presupuestos, Schmitt sostuvo que:

[...] la renuncia del fascismo a las elecciones, la aversión y el menosprecio que profesa por el elezionismo, de ninguna manera son actitudes antidemocráticas sino antiliberales, derivadas de la observación correcta de que los métodos actuales de votación uninominal secreta ponen en peligro la esencia del Estado y de la política por medio de la privatización total, eliminan completamente del ámbito político al pueblo como unidad —el soberano desaparece en la cabina electoral - y degradan la formación de la voluntad estatal al convertirla en la suma de las voluntades individuales privadas y secretas, es decir, de los deseos y resentimientos en realidad incontrolables de las masas. ${ }^{22}$

Contribuye con esta distorsión del concepto del poder constituyente, la afirmación de que en toda sociedad política existen dos constituciones diferentes: la Constitución formal y la Constitución material. Sus defensores sostienen que la primera es la Constitución escrita, mientras que la segunda es la forma efectiva de la vida política jurídica de un Estado. Al mismo tiempo, afirman que el objetivo fundamental de una sociedad política consiste en lograr que su Constitución formal sea expresión de su Constitución material. El problema es que esta tesis puede servir para afirmar que la estructura autocrática existente en una sociedad política - por el solo hecho de ser efectiva- conforma la Constitución material a la cual debe adecuarse la Constitución formal. Con un argumento semejante, Carl Schmitt sostuvo que la Rusia bolchevique y la Italia fascista eran los dos únicos Estados que habían «[...] intentado romper con el tradicional cliché constitucional del siglo XIX y reflejar los grandes cambios en la estructura económica y social del país también en su organización estatal y en una nueva constitución escrita». ${ }^{23}$

Por lo tanto, este empleo de la distinción entre Constitución formal y Constitución material resulta incompatible con la democracia constitucional. No olvidemos que, desde la perspectiva de este sistema político, en ningún lugar es aceptable la existencia de una autocracia, ni siquiera cuando esta se encuentre consolidada por la aclamación popular. Al respecto, Gonzalo A. Ramírez Clevez afirma lo siguiente:

21 Schmitt, Carl. «El Führer defiende el Derecho (1934)». En Carl Schmitt. Teólogo de la política. Prólogo y selección de textos de Héctor Orestes Aguilar. México: Fondo de Cultura Económica, 2001, p. 115.

22 Schmitt, Carl. «El Ser y el devenir del Estado fascista (1929)». En Carl Schmitt. Teólogo de la política. Prólogo y selección de textos de Héctor Orestes Aguilar. México: Fondo de Cultura Económica, 2001, p. 77.

23 Ibíd., p. 78. 
Negamos pues que el valor dominante por ejemplo de un proyecto totalitario, autoritario o autocrático, pueda fundamentar las leyes o el derecho que produce acudiendo a la decisión democrática y afirmar que se trata de la Constitución del pueblo que la legitimó. En este caso se presentaría un contrasentido porque la solución democrática cerraría a futuro sus posibilidades, se autodestruiría y no permitiría garantizar la libertad de autorregulación en el porvenir. ${ }^{24}$

\section{La Asamblea Constituyente como instrumento para el ejercicio del poder constituyente}

Nicola Mateucci explica que uno de los elementos en los que se basa la legitimidad de una Constitución escrita es su fuente formal, «[...] por emanar de la voluntad soberana del pueblo a través de una asamblea constituyente y, a veces, de un referéndum». ${ }^{25}$ Esto significa que la Asamblea Constituyente es un instrumento que puede ser empleado por las personas para, en ejercicio del poder constituyente, elaborar una Constitución, es decir, realizar el reconocimiento de sus derechos fundamentales y el diseño de la estructura organizativa concreta del sistema constitucional de su sociedad política, y también para realizar la revisión total de su Constitución vigente, sin seguir los procedimientos que esta regula para realizar su modificación.

Sin embargo, es necesario tener presente que las asambleas constituyentes también pueden ser utilizadas como instrumentos al servicio de sistemas autocráticos. No olvidemos que la dictadura en la Rusia soviética empezó su marcha con la convocatoria a una Asamblea Constituyente, que había sido reclamada por los bolcheviques desde 1903. ${ }^{26}$ Por su parte, George Liet-Veaux recuerda que el programa del partido fascista «[...] conducía a la abolición del Senado y la convocatoria de una Asamblea Constituyente». ${ }^{27}$

Para evitar que una Asamblea Constituyente se convierta en el punto de partida de sistemas autocráticos es imprescindible, en primer lugar, que su

24 Ramírez Cleves, Gonzalo A. Límites de la reforma constitucional en Colombia. El concepto de Constitución como fundamento de la restricción. Bogotá: Universidad Externado de Colombia, 2005, pp. 279-280.

25 Matteucci, Nicola. Organización del poder y libertad. Historia del constitucionalismo moderno. Madrid: Editorial Trotta, 1998, p. 25.

26 Carr E. H. La Revolución Bolchevique (1917-1923). I. La conquista y la organización del poder. Madrid: Alianza Editorial S.A., 1985, p. 103.

27 Liet-Veaux, George. «El «fraude a la Constitución». Ensayo de un análisis jurídico de las recientes revoluciones políticas: Italia, Alemania, Francia». En Revista de Derecho Público, Administrativo y Constitucional, núm. 10, enero-junio 2005, Editorial Jurídica Grijley, LimaPerú, p. 18. 
convocatoria sea resultado del consenso. Este consenso consiste en la común intención de las tendencias políticas presentes en una sociedad de crear una estructura organizativa completa para el sistema constitucional, o de revisar totalmente la organización existente pero — debido a circunstancias especiales_- prescindiendo de los mecanismos que la Constitución establece para su reforma. No podrá ser, por consiguiente, el resultado de la imposición de una mayoría política eventual, por más considerable que sea su dimensión numérica. Al respecto, Pedro Planas explica que toda Constitución «[...] por antonomasia, debería ser una norma de consenso, en tanto se trata de un pacto institucional de carácter supragubernamental, ubicado más allá de las tendencias eventuales de un partido mayoritario o del gobierno de turno ${ }^{28}$ y que los requisitos para considerar que una Constitución es de consenso son: a) en el escenario electoral: la plural participación de las fuerzas políticas, b) en el escenario político: la autonomía garantizada de la labor constituyente frente al gobierno y a los deseos y necesidades del poder, y c) en la labor constituyente: el libre debate, con vocación de diálogo y acuerdo entre las fuerzas políticas participantes. ${ }^{29}$

Gonzalo Ramírez Cleves, por su parte, explica, en cuanto a la convocatoria de las asambleas constituyentes que, aunque en la mayoría de los casos

[...] estas no se proclaman a sí mismas, y surgen de circunstancias críticas o revolucionarias, se sostiene que en las elecciones en que se nombre a los representantes constituyentes se debe observar el cumplimiento de los derechos y libertades civiles y políticas, dándose una representación proporcional que dé cabida a las minorías políticas. ${ }^{30}$

Además, este autor afirma que:

[...] la participación efectiva del pueblo como sujeto del poder constituyente se deduce cuando se comprueba que durante la etapa previa, en el proceso constituyente y en la incorporación final de la normatividad constitucional — con referéndum o sin él一 se pusieron en práctica las garantías y principios propios del ejercicio de la democracia. ${ }^{31}$

28 Planas, Pedro. «La Constitución peruana de 1993 ¿Es una Constitución de consenso?». En Anuario de Derecho Constitucional Latinoamericano, edición 1999, Konrad Adenauer Stiftung, CIEDLA, Centro Interdisciplinario de Estudios sobre el Desarrollo Latinoamericano, Buenos Aires-Argentina, 1999, p. 557.

29 lbíd., pp. 557-558.

30 Ramírez Cleves, Gonzalo A. Límites de la reforma constitucional en Colombia. El concepto de Constitución como fundamento de la restricción. Bogotá-Colombia: Universidad Externado de Colombia, 2005, pp. 274-275.

$31 \quad$ lbíd., p. 276. 
Un ejemplo de la realización de una Asamblea Constituyente en un clima de consenso se produjo en el Perú, en los años 1978 y 1979. Entonces, según explica Pedro Planas, con prescindencia de encontrarse en el ejercicio del poder político un gobierno militar de facto, se presentaron las siguientes condiciones favorables para el ejercicio genuino del poder constituyente: a) ninguna agrupación política obtuvo mayoría absoluta en la Asamblea y b) no hubo intervención alguna del poder político que obstaculizara la reflexión institucional. ${ }^{32}$ Además, Pedro Planas recuerda que, en ese momento, el régimen militar se encontraba de salida $y$, «[... que con la convocatoria a la Asamblea Constituyente, el gobierno de Morales Bermúdez cumplía el compromiso asumido en el plan Tupac Amaru de iniciar el proceso de transferencia del poder». ${ }^{33}$ Asimismo, en mayo de 1977, es decir, tiempo antes de la aprobación de este plan, el gobierno había iniciado un diálogo con diversos partidos, concerniente a la forma en que debía finalizar el régimen dictatorial que, en ese momento, se encontraba en funcionamiento. ${ }^{34}$

A pesar de lo expuesto, se ha pretendido objetar el carácter consensual de este proceso político. Se afirmó, en primer lugar, que la ausencia de Acción Popular - partido que, entonces, contaba con amplio respaldo popular-en las elecciones para la Asamblea Constituyente significó el desconocimiento de su legitimidad. Por otra parte, se ha sostenido que esta deslegitimación radica en el hecho que los representantes constituyentes de los partidos de izquierda se negaron a firmar el texto constitucional aprobado por la Asamblea.

Respecto de la abstención de Acción Popular, es imprescindible recordar que este partido inicialmente tuvo la intención de participar en las elecciones para la Asamblea Constituyente de 1978-1979. Así, según informó el diario La Prensa, el 8 de enero de 1978 en un mitin realizado en el Cuzco, Fernando

22 Planas, Pedro. Ob. cit., pp. 558-559.

33 Ibíd., p. 559. En el contenido del Plan Túpac Amaru se indicó que, uno de los objetivos generales para lograr su finalidad, era «Institucionalizar, a través de una Constitución, las reformas estructurales haciéndoles los indispensables reajustes que la experiencia aconseja» (Plan de gobierno Túpac Amaru, aprobado por decreto supremo 020-77-PM del 4 de octubre de 1977, período 1977-1980, edición no oficial, extracto del Diario Oficial El Peruano, p. 7).

34 «En el diálogo el APRA planteó la necesidad de elecciones municipales, elecciones para una Asamblea Constituyente a mediados de 1978 y elecciones generales para 1980. Acción Popular Belaundista señaló la necesidad de realizar elecciones el próximo año y entregar el poder el 28 de julio. El Partido Popular Cristiano planteó un Poder Legislativo que funcione entre 1978 y 1980, y que la Fuerza Armada quede a cargo del Ejecutivo hasta 1980 en que sea renovado medio Congreso y el Ejecutivo. El Partido Comunista, Acción Popular Socialista y la Democracia Cristiana no hicieron un planteo sobre elecciones y esta última advirtió que si el regreso al poder de los civiles significase el retroceso o la liquidación de la revolución «sería preferible que siga el régimen actual»». En PeAse García, Henry. Los caminos del poder. Tres años de crisis en la escena política. Lima: DESCO, Centro de Estudios y Promoción del Desarrollo, 1979, p. 213. 
Belaunde Terry —líder de este partido político— «[...] dijo que la próxima Asamblea Constituyente debe inaugurar un nuevo gobierno democrático y civil para empezar la reconstrucción de nuestra economía». ${ }^{35}$ Pocos días después —el 11 de enero del mismo año—, Belaunde Terry indicó «[...] que, a pesar de las limitaciones de la Asamblea Constituyente su partido ha tomado la convocatoria como un reto y 'vamos a participar de todas maneras en las elecciones'». ${ }^{36}$ Posteriormente, de forma sorpresiva, Acción Popular decidió «[...] no participar en las elecciones para la Asamblea Constituyente». ${ }^{37}$ Según el comunicado leído en conferencia de prensa por el dirigente de este partido, Fernando Schwalb López Aldana, esta decisión se debió a que «[...] el Gobierno no aclaró debidamente las dudas en torno a la Asamblea Constituyente». ${ }^{38}$ Sin embargo, Manuel Ulloa — también dirigente de Acción Popular- sostuvo que esta abstención «no significa boicotear las elecciones». ${ }^{39}$

Como se puede apreciar, la abstención de Acción Popular no significó un rechazo intransigente que produjera la deslegitimación del funcionamiento de la Asamblea Constituyente de 1978-1979. Por el contrario, Fernando Belaunde Terry, durante el funcionamiento de esa Asamblea, envió al presidente de su Comisión Principal de Constitución un Memorandum sobre la Reforma Constitucional en el cual agradeció la comunicación mediante la cual le habían solicitado sugerencias y propuestas para el proyecto de Constitución a cargo de dicha Comisión, e incluyó un documento que contenía sus puntos de vista respecto de las enmiendas, supresiones y adiciones que, en su opinión, debía sufrir la Constitución de $1933 .{ }^{40}$ Además, posteriormente, Acción Popular participó decisivamente en la construcción del consenso posterior favorable a la Constitución elaborada por esta Asamblea. Así, según explica Pedro Planas, pese a que Acción Popular no participó en la Asamblea Constituyente de 19781979, Fernando Belaunde Terry, «[...] como Presidente de la República, cumplió, juró cumplir y desarrolló legislativamente la Constitución de 1979». ${ }^{41}$ De este modo — continúa Pedro Planas—, «Fernando Belaunde y AP se integraron y fortalecieron el consenso constitucional de la Asamblea Constituyente, haciendo converger sus propias iniciativas y voluntades en la legitimación

\footnotetext{
En Perú 1978. Cronología política. Tomo VII. Lima: Desco, Centro de Estudios y Promoción del Desarrollo, 1980, p. 2939.

36 Ibíd., p. 2946.

Ibíd., p. 2999.

Ibíd., p. 3000

lbíd.

40 En Bernales Ballesteros, Enrique y Rubio Correa, Marcial. Constitución: fuentes e interpretación. Teoría y documentación del proceso constitucional y la Constitución de 1979. Lima: Mesa Redonda Editores S.A., 1988, pp. 199-205.

41 Planas, Pedro. Ob. cit., p. 573.
} 
jurídica, política y social de la Constitución de 1979, como también sucedió con algunos sectores de izquierda, inicialmente distantes respecto al texto constitucional de 1979».42

En cuanto a los partidos de izquierda en el Perú, cuyos representantes rechazaron firmar el texto de la Constitución de 1979, es necesario tener presente que muchos de ellos contribuyeron también a consolidar el consenso posterior favorable a este ordenamiento constitucional. Así, no solo participaron, en mayo de 1980, en las elecciones generales para elegir al presidente constitucional de la República y a los diputados y senadores, previstos en la Constitución de 1979, sino que, además, en 1983, Alfonso Barrantes Lingán, candidato de Izquierda Unida, postuló y resultó elegido alcalde metropolitano de la ciudad de Lima, en las elecciones municipales realizadas de conformidad con este ordenamiento constitucional.

A estas circunstancias de consenso, propicias para la convocatoria de una Asamblea Constituyente que asuma la tarea de construir una estructura organizativa del sistema constitucional o de modificarla prescindiendo de los requerimientos formales establecidos en la Constitución vigente, se les denomina momento constituyente. Este momento constituyente estuvo presente también en 1990, cuando fue elegida la Asamblea que aprobó la Constitución vigente actualmente en Colombia. Según explica Pedro Planas, en esa oportunidad la convocatoria a elecciones constituyentes estuvo precedida por un consenso ciudadano y fue posible por la iniciativa de estudiantes universitarios. ${ }^{43}$

Esta iniciativa consistió en la propuesta de incluir una séptima papeleta en apoyo de la convocatoria a una Asamblea Constituyente, en las elecciones del 11 de marzo de 1990, en las cuales «[...] se elegirían: alcaldes, concejales, diputados, representantes a la Cámara, senadores y candidato liberal por consulta popular». ${ }^{44} \mathrm{El}$ resultado inmediato fue de "[...] dos millones doscientos mil electores que votaron por la Constituyente». ${ }^{45}$ Posteriormente, el 3 de mayo de 1990, el gobierno expidió el decreto de estado de sitio 927 que facultaba a la Registraduría para contabilizar los votos que se emitieran en las elecciones presidenciales del 27 de mayo de 1990 «[...] en torno a la convocatoria de una Asamblea Constitucional». ${ }^{46}$ Tres días antes de las elecciones —en las

42 Ibíd.

43 Planas, Pedro. Regímenes políticos contemporáneos. Lima: Fondo de Cultura Económica, 1997, pp. 496.

44 Dávila Ladrón de Guevara, Andrés. El Frente Nacional y el proceso constituyente del 91. Bogotá: Universidad de los Andes, CESO, Departamento de Ciencia Política, Alfaomega Colombiana, 2002, p. 113.

45 Ibíd.

46 Ibíd., p. 114. 
que resultó elegido Cesar Gaviria como presidente de Colombia-, la sentencia 59 de la Corte Suprema declaró constitucional este decreto, y una vez que se realizaron los comicios el resultado a favor de la convocatoria a una Asamblea Constitucional fue contundente "con un $89 \%$ de votos por el Si». ${ }^{47}$ Luego de ello, el presidente electo convocó a las demás fuerzas a un acuerdo político, el cual se firmó, determinándose ahí el procedimiento de conformación, la composición, el temario y los controles de la Asamblea. ${ }^{48} \mathrm{El}$ acuerdo se ratificó semanas después de que Gaviria asumiera el gobierno y al día siguiente el presidente expidió el decreto de estado de sitio 1926, convocando a elecciones constituyentes. ${ }^{49}$ La Corte Suprema, el 9 de octubre de 1990, declaró parcialmente constitucional este decreto, porque sostuvo que eran inexequibles -inconstitucionales - las limitaciones introducidas en cuanto al temario,

[...] pues consideró que la nación como constituyente primario era soberana y no se le podía coartar su iniciativa en cuanto a la determinación de su Carta Constitucional y las reformas que a ella considerara necesario hacerle: la Corte ratificó la prohibición de modificar el período de los elegidos en 1990 y las inhabilidades de los constituyentes para aspirar electoralmente a cargos populares en 1992 y 1994. En pocas palabras, el fallo de la Corte dio pie para que de ahí en adelante se hablara de Asamblea Constituyente. ${ }^{50}$

Después de esta declaración de la Corte Suprema, el 9 de diciembre de 1990, fueron elegidos los setenta miembros de la Asamblea Nacional Constituyente $(\mathrm{ANC})^{51}$ que elaboró la Constitución colombiana actualmente en vigencia.

\section{La Asamblea Constituyente como instrumento para la reforma constitucional}

El poder de reforma constitucional consiste en la atribución de revisar la Constitución, con la finalidad de modificar su contenido, siguiendo los procedimientos expresamente previstos en el ordenamiento constitucional. La reforma será parcial cuando se encuentre dirigida a modificar una parte de la Constitución y será total cuando sea emprendida para someter a revisión la totalidad del contenido del ordenamiento constitucional. En el Perú —como

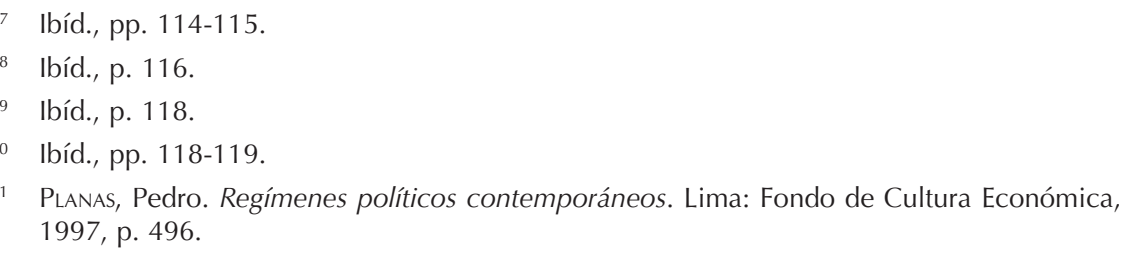


ocurre en España, de conformidad con el artículo 168 de su Constitución-, ${ }^{52}$ se encuentra permitida la reforma total de la Constitución..$^{33}$ Sin embargo, es necesario tener presente que, tal como ocurre con el ejercicio del poder constituyente, el empleo del poder de reforma constitucional en ningún caso puede ser utilizado válidamente para destruir el sistema constitucional.

Según explica Pedro de Vega, la reforma constitucional en la moderna organización democrática cumple tres funciones básicas: sirve como instrumento de adecuación entre la realidad jurídica y la realidad política; constituye un mecanismo de articulación de la continuidad jurídica del Estado; y representa una institución básica de garantía. ${ }^{54}$ Respecto de los orígenes de este poder de reforma, Javier Pérez Royo sostiene que, fueron los Estados Unidos «[...] los que introdujeron la técnica de la reforma constitucional como instrumento democrático de protección de la supremacía de la Constitución sobre los poderes constituidos». ${ }^{55}$ Sobre las mismas circunstancias fundacionales de esta institución, Roberto Blanco Valdés explica que la Constitución norteamericana

52 Constitución de España: «Artículo 168:

1. Cuando se propusiere la revisión total de la Constitución o una parcial que afecte al Título Preliminar, al Capítulo Segundo, Sección Primera del Título I, o al Título II, se procederá a la aprobación del principio por mayoría de dos tercios de cada Cámara, y a la disolución inmediata de las Cortes.

2. Las Cámaras elegidas deberán ratificar la decisión y proceder al estudio del nuevo texto constitucional, que deberá ser aprobado por mayoría de dos tercios de ambas cámaras.

3. Aprobada la reforma por las Cortes Generales, será sometida a referéndum para su ratificación».

53 Constitución Política del Perú. «Artículo 32.- Pueden ser sometidas a referéndum:

1. La reforma total o parcial de la Constitución;

2. La aprobación de normas con rango de ley;

3. Las ordenanzas municipales; y

4. Las materias relativas al proceso de descentralización.

No pueden someterse a referéndum la supresión o la disminución de los derechos fundamentales de la persona, ni las normas de carácter tributario y presupuestal, ni los tratados internacionales en vigor».

«Artículo 206.- Toda reforma constitucional debe ser aprobada por el Congreso con mayoría absoluta del número legal de sus miembros, y ratificada mediante referéndum. Puede omitirse el referéndum cuando el acuerdo del Congreso se obtiene en dos legislaturas ordinarias sucesivas con una votación favorable, en cada caso, superior a los dos tercios del número legal de congresistas. La ley de reforma constitucional no puede ser observada por el Presidente de la República.

La iniciativa de reforma constitucional corresponde al Presidente de la República, con aprobación del Consejo de Ministros; a los congresistas; y a un número de ciudadanos equivalente al cero punto tres $(0.3 \%)$ de la población electoral, con firmas comprobadas por la autoridad electoral».

54 De VeGA, Pedro. La reforma constitucional y la problemática del poder constituyente. Madrid: Editorial Tecnos S.A., 1999, p. 67.

55 Pérez Royo, Javier. La reforma de la Constitución. Madrid: Publicaciones del Congreso de los Diputados, 1987, p. 23. 
de 1787 «[...] supuso la definición en la teoría de la Constitución del poder de reforma constitucional, como un poder político específico, distinto por su naturaleza y significación de los poderes ordinarios (constituidos) del Estado». ${ }^{56}$

Entre los procedimientos que las constituciones contemplan para realizar la reforma constitucional se encuentra el reconocimiento de la posibilidad de convocar una Asamblea Constituyente pero, en este caso, estableciendo en el propio texto constitucional ciertos límites formales a su funcionamiento. Así, por ejemplo, el artículo 374 de la Constitución de Colombia ${ }^{57}$ prescribe que esta podrá ser reformada por el Congreso, por una Asamblea Constituyente o por el pueblo mediante referéndum, mientras que su artículo $376^{58}$ establece que el Congreso, mediante una ley, podrá disponer que el pueblo en votación popular decida si convoca a una asamblea constituyente con la competencia, el período y la composición que la ley determine.

Otro caso se presenta en Bolivia, donde actualmente se encuentra en funciones una Asamblea Constituyente prevista en el ordenamiento constitucional actualmente vigente en ese país. La Constitución boliviana, en su artículo $232^{59}$ — que forma parte del título II de su parte IV— establece que su reforma total es potestad privativa de la Asamblea Constituyente, que será convocada por ley especial de convocatoria, en la cual se señalará las formas y modalidades de elección de los constituyentes, será sancionada por dos tercios de

56 Blanco VAldés, Roberto. El valor de la Constitución. Separación de poderes, supremacía de la ley y control de constitucionalidad en los orígenes del Estado liberal. Madrid: Alianza Editorial S.A., 1988, p. 120. Este autor explica, además, que por «[...] más que sea posible encontrar antecedentes remotos a tal poder de reforma y aun antecedentes próximos en algunas de las Cartas de los Estados previas a la Unión, es lo cierto que cualquiera de ellos carecerá de la entidad irradiante que iba a tener hacia el futuro el artículo $V$ de la Constitución norteamericana», norma en la cual se encuentran regulados sus procedimientos de reforma. (Ob. cit., pp. 120-121).

57 Constitución Política de Colombia. «Artículo 374.- La Constitución Política podrá ser reformada por el congreso, por una asamblea constituyente o por el pueblo mediante referendo».

58 Constitución Política de Colombia. «Artículo 376.- Mediante ley aprobada por mayoría de los miembros de una y otra cámara, el congreso podrá disponer que el pueblo en votación popular decida si convoca una asamblea constituyente con la competencia, el período y la composición que la misma ley determine.

Se entenderá que el pueblo convoca la asamblea, si así lo aprueba, cuando menos, una tercera parte de los integrantes del censo electoral.

La asamblea deberá ser elegida por el voto directo de los ciudadanos, en acto electoral que no podrá coincidir con otro. A partir de la elección quedará en suspenso la facultad ordinaria del congreso para reformar la Constitución durante el término señalado para que la asamblea cumpla sus funciones. La asamblea adoptará su propio reglamento».

59 Constitución Política de Bolivia. «Artículo 232.- La Reforma total de la Constitución Política del Estado es potestad privativa de la Asamblea Constituyente, que será convocada por Ley Especial de convocatoria, la misma que señalará las formas y modalidades de elección de los constituyentes, será sancionada por dos tercios de voto de los miembros presentes del $\mathrm{H}$. Congreso Nacional y no podrá ser vetada por el Presidente de la República». 
votos de los miembros presentes del Honorable Congreso Nacional y no podrá ser vetada por el presidente de la República. En concordancia con esta disposición, se expidió la Ley Especial de Convocatoria a la Asamblea Constituyente, el 6 de marzo de 2006, cuyo artículo $25^{60}$ prescribe que, de conformidad con lo establecido por el título II de la parte IV de la Constitución, el texto de la nueva Constitución se deberá aprobar con dos tercios de votos de miembros presentes en la Asamblea. El artículo 26 de esta misma ley, ${ }^{61}$ además, dispone que concluida la misión de la Asamblea, el Poder Ejecutivo convocará a referéndum constituyente.

\section{Conclusiones}

1. El poder constituyente es la atribución que corresponde a las personas para elaborar una Constitución, es decir, para establecer el reconocimiento de sus derechos fundamentales y para crear la estructura organizativa concreta del sistema democrático constitucional correspondiente a su sociedad política.

2. El poder constituyente es un elemento fundamental del sistema democrático constitucional. Por consiguiente, como expresión de autogobierno de las personas, no puede ser utilizado válidamente por estas para renunciar al reconocimiento de sus derechos ni a la posibilidad de decidir libremente acerca de la organización de su régimen político.

3. La Asamblea Constituyente es un instrumento que sirve para que las personas, en ejercicio del poder constituyente, puedan elaborar una Constitución, es decir, para que puedan realizar el reconocimiento de sus derechos fundamentales y el diseño de la estructura organizativa concreta del sistema constitucional de su sociedad política. También sirve para que las personas integrantes de una sociedad política puedan realizar la revisión total de la Constitución vigente, sin seguir los procedimientos de modificación regulados en esta.

60 Ley Especial de Convocatoria a la Asamblea Constituyente - Bolivia. «Artículo 25 (Aprobación del Texto Constitucional). La Asamblea Constituyente aprobará el texto de la nueva Constitución con dos tercios de votos de los miembros presentes de la Asamblea, en concordancia con lo establecido por Título II de la Parte IV de la actual Constitución Política del Estado».

61 Ley Especial de Convocatoria a la Asamblea Constituyente - Bolivia. «Artículo 26 (Referéndum Constituyente). Concluida la misión de la Asamblea Constituyente, el Poder Ejecutivo convocará a referéndum Constituyente, en un plazo no mayor a ciento veinte días a partir de la convocatoria. En dicho Referéndum, el pueblo boliviano refrendará, por mayoría absoluta de votos, el proyecto de la nueva Constitución en su totalidad, propuesto por la Asamblea Constituyente». 
4. Para evitar que una Asamblea Constituyente se convierta en un instrumento para construir un sistema autocrático, es imprescindible que su convocatoria sea resultado de un consenso. Este debe consistir en la común intención de las tendencias políticas, presentes en una sociedad, de crear una estructura organizativa completa para el sistema constitucional, o de revisar totalmente la organización existente de este sistema, pero — debido a circunstancias especiales - prescindiendo de los mecanismos que la Constitución vigente establece para su reforma.

5. La Asamblea Constituyente también puede ser parte integrante de los procedimientos que las constituciones contemplan para realizar una reforma constitucional. Sin embargo, en estos casos, las mismas constituciones son las que establecen límites a su funcionamiento. 